\title{
Importance of Cuff Cytology and Human Papillomavirus Screening, Especially in Patients with Autoimmune Disorders
}

(1) Canan ÜNAL

D Hanife Güler DÖNMEZb'

(1) Erdem FADILOĞLUa,

(D) Atakan TANAÇANa,

(D) M. Sinan BEKSAÇa

Departments of

aGynecology and Obstetrics,

Division of Perinatology,

${ }^{\mathrm{b} B i o l o g y,}$

Hacetepe University Faculty of Medicine, Ankara, TURKEY

Received: 04.02.2019

Received in revised form: 27.02.2019

Accepted: 28.02.2019

Available online: 19.03 .2019

Correspondence:

Canan ÜNAL

Hacetepe University Faculty of Medicine, Department of Gynecology and Obstetrics Division of Perinatology,

Ankara, TURKEY

unal_canann@ hotmail.com
Copyright @ 2019 by Türkiye Klinikleri

\begin{abstract}
This article aims to report the results of four cases of human papillomavirus (HPV) positivity and abnormal cuff smear. A hysterectomy was performed in this study to eliminate precancerous cervical lesion in one patient and uterine myoma in another. Subsequent follow-up of the patients revealed HPV DNA positivity in cuff cytology, even though both the patients tested negative for HPV prior to hysterectomy. Cuff cytology and HPV DNA screening, therefore, seem to be important in dicey and benign cases, especially occurring together with autoimmune disorders. HPV type 16 was found to be the most frequent subtype (75\%) in this study.
\end{abstract}

Keywords: Cytology; human papilloma virus 16; human papilloma virus DNA test; autoimmune disorders

fter total hysterectomy, except that in women with a history of cervical cancer or Cervical Intraepithelial Neoplasia (CIN) II/CIN III/High-grade Squamous Intraepithelial Lesion (HSIL), routine vaginal cuff cytology screening is not recommended, if the hysterectomy was performed for benign uterine conditions like uterine fibroids, endometriosis/adenomyosis, uterine prolapse or urinary incontinence. ${ }^{1,2} \mathrm{How}^{-}$ ever, different studies report various percentages of high-risk HPV and premalignant changes in a cuff smear, which range from $4.5-9.5 \%{ }^{1}$ Vaginal intraepithelial neoplasia was found to develop in nearly $7.4 \%$ of the patients in a study wherein a hysterectomy was performed for HSIL/CIN III. ${ }^{3}$ Vaginal cancer is rare, comprising only about $1-4 \%$ of the lower genital tract cancers; the rate of progression of vaginal intraepithelial neoplasia into invasive vaginal cancer ranges from $0-9 \%{ }^{4-7}$

Cuff smear cytology is often ignored due to the rarity of vaginal cancer and the fact that its progression rate is lower than that of cervical cancer. There is no clear conformity on the matter of cuff smear cytology following total hysterectomy, especially in benign cases. Therefore, the authors aim to report the results of four female patients with HPV positivity and abnormal cuff smear in whom total hysterectomy was performed.

\section{CASE REPORTS}

This case series reports the results of four patients with HPV positivity after they underwent routine gynecologic follow-up after a hysterectomy. The 
first case, a 50-year-old patient, having systemic lupus erythematosus (SLE), Hashimoto's thyroiditis, chronic viral hepatitis B infection and mitral valve prolapse reported with a history of left oophorectomy due to the benign mucinous cyst and cesarean section 16 years ago. The patient also underwent a total hysterectomy and unilateral salpingo-oophorectomy, performed to eliminate uterine myoma, eight years ago. Pap smear tests and HPV screening were performed regularly during the postoperative period; HPV-DNA positivity of types 59 and 82 was found in the patient in 2018. Pap smear test revealed Atypical Squamous Cells of Undetermined Significance (ASCUS). The only complaint of the patient during this period was a slight pelvic pain.

The second patient, 53 years old, reported with a history of operated breast carcinoma, chronic gastritis, and anti-TSH receptor antibody positivity. This patient also had a history of total abdominal hysterectomy and bilateral salpingooophorectomy performed ten years ago for uterine myoma. Gynecologic follow-up examinations were found to be normal until 2018, with no complaints. HPV and smear tests revealed positivity of HPV type 16 and Low-grade Squamous Intraepithelial Lesion (LSIL).

The third patient, 41 years old, reported with a history of metastatic colon carcinoma and positivity of anti-parietal antibody. The results of the Pap smear and HPV test were observed to be HSIL and HPV type 16 positive in 2013. The patient underwent Loop Electrosurgical Excision Procedure (LEEP) and cervical conization as per the international guidelines. ${ }^{8}$ Positive surgical margin was obtained after the cervical conization and a hysterectomy was thus planned for the patient. Total abdominal hysterectomy and unilateral salpingo-oophorectomy had already been performed on the patient in 2014 for HSIL/CIN III and ovarian cysts. No abnormal bleeding, discharge or pelvic pain was reported during the postoperative period. During the postoperative follow-up, HPV type 16 was found to be positive and the smear result reported LSIL.
The fourth patient, 50 years old, reported with a history of diabetes mellitus type 2, Myasthenia gravis, epilepsy, Hashimoto's thyroiditis, and positivity for the anti-nuclear antibody, anti-cardiolipin antibody, and anti-Ds DNA antibody. The patient underwent a total abdominal hysterectomy and unilateral salpingo-oophorectomy for uterine myoma and HSIL/CINIII in 2004. Smear tests after hysterectomy were found to be normal without any gynecological complaints. Yet, HPV DNA test recorded positive for type 16 and the Pap smear was found to be LSIL during the routine examination carried out in 2018.

In all the cases, the patients had single partners and none of them or the partners had a history of suspicious sexual intercourse in terms of sexually transmitted diseases. However, the partner's HPV status was unknown. Colposcopy and biopsy were performed for all patients, once abnormal smears and the presence of HPV DNA positivity were detected.

Informed consent was obtained from all patients prior to the study.

\section{DISCUSSION}

Vaginal cancer is a rare disease and accounts for 1$4 \%$ of all genital cancers. It has a prevalence of $0.4-$ 0.6 per 100,000 females. ${ }^{4,5}$ The risk factors for vaginal cancer include the presence of HPV, other gynecological neoplasias or cancers, smoking, radiation therapy, immunosuppression, and diethylstilbestrol. ${ }^{9}$ The history of a previous total hysterectomy performed for CIN II/CIN III is an important risk factor for Vaginal Intra-epithelial Neoplasia (VAIN). While the rate of VAIN was found to be $1.1 \%$ in females who underwent hysterectomy for benign conditions, this rate increased to $7.4 \%$ in women who underwent hysterectomy for CIN III. ${ }^{10}$ In this small case series, HPV DNA positivity and abnormal Pap smear were detected in the first decade after the surgery.

It has been reported that type 16 and 18 are the most frequent types of HPV having an incidence of 4.5-9.5\%. ${ }^{3,11-13}$ In this study, three of the cases were found to be positive for HPV type 16 (75\%). Previous studies have demonstrated that HPV type 16 in- 
creases the risk of cervical, vulvar, vaginal, anal, head, neck, and oropharyngeal cancers significantly. ${ }^{14,15}$ The presence of HPV type 16 is essential for the transformation of normal epithelial cells from premalignant to malignant, and long-term persistence of infections. ${ }^{16}$ Therefore, the patients with HPV type 16 positivity should be followedup more closely. Recent studies showing the predilection of certain HPV groups to vaginal epithelium may encourage the physicians to continue HPV and vaginal smear studies in hysterectomized women, even in the absence of a history of cervical abnormality. ${ }^{17}$ Although two patients in this case series underwent hysterectomy for benign reasons, HPV DNA was positive, which is in accordance with the previous findings in the literature.

Follow-up of the patients is performed according to the recent recommendations and international guidelines. ${ }^{9}$ The patients with low-grade cytology result (ASCUS/LSIL) or high-risk HPV DNA positivity are recommended vaginal cytology control. The patients with cytology ASC-H are referred for vaginal colposcopy. Colposcopy is also recommended for the suspicious lesions detected during vaginal examinations.

The increased prevalence of high-risk HPV, multiple HPV infections and an elevated risk of high-grade cervical dysplasia were detected in women with autoimmune disorders like SLE and Rheumatoid Arthritis (RA). ${ }^{18-21}$ According to the different studies, patients with high inflammatory load are at risk of HPV infection and the persistence of HPV infection after total hysterectomy. However, in this study, all patients had a history of autoimmune disorder.

In conclusion, cuff cytology and HPV DNA screening seem to be important in uncertain and benign cases, especially those that occur in conjunction with autoimmune disorders.

\section{Source of Finance}

During this study, no financial or spiritual support was received neither from any pharmaceutical company that has a direct connection with the research subject, nor from a company that provides or produces medical instruments and materials which may negatively affect the evaluation process of this study.

\section{Conflict of Interest}

No conflicts of interest between the authors and / or family members of the scientific and medical committee members or members of the potential conflicts of interest, counseling, expertise, working conditions, share holding and similar situations in any firm.

\section{Authorship Contributions}

Idea/Concept: M. Sinan Beksaç, Design: Hanife Güler Dönmez, Control/Supervision: M. Sinan Beksaç, Data Collection and/or Processing: Canan Ünal, Hanife Güler Dönmez, Analysis and/or Interpretation: Erdem Fadıloğlu, Atakan Tanaçan, Literature Review: Canan Ünal, Hanife Güler Dönmez, Writing the Article: Canan Ünal, Hanife Güler Dönmez, Critical Review: Atakan Tanaçan.

\section{REFERENCES}

1. Videlefsky A, Grossl N, Denniston M, Sehgal $\mathrm{R}$, Lane JM, Goodenough G. Routine vaginal cuff smear testing in post-hysterectomy patients with benign uterine conditions: when is it indicated? J Am Board Fam Pract. 2000;13(4):233-8. [Crossref] [PubMed]

2. Neis KJ, Zubke $\mathrm{W}$, Fehr $\mathrm{M}$, Römer $\mathrm{T}$, Tamussino K, Nothacker M. Hysterectomy for benign uterine disease. Dtsch Arztebl Int. 2016;113(14):242-9. [Crossref]

3. Bansal M, Austin RM, Zhao C. Correlation of histopathologic follow-up findings with vaginal human papillomavirus and low-grade squamous intraepithelial lesion Papanicolaou test results. Arch Pathol Lab Med. 2011;135(12):1545-9. [Crossref] [PubMed]
4. Rajaram S, Maheshwari A, Srivastava A. Staging for vaginal cancer. Best Pract Res Clin Obstet Gynaecol. 2015;29(6):822-32. [Crossref] [PubMed]

5. Aho M, Vesterinen E, Meyer B, Purola E, Paavonen J. Natural history of vaginal intraepithelial neoplasia. Cancer. 1991;68(1): 195-7. [Crossref]

6. Frega A, French D, Piazze J, Cerekja A, Vetrano G, Moscarini M. Prediction of persistent vaginal intraepithelial neoplasia in previously hysterectomized women by high-risk HPV DNA detection. Cancer Lett. 2007;249(2):23541. [Crossref] [PubMed]

7. So KA, Hong JH, Hwang JH, Song $\mathrm{SH}$, Lee JK, Lee NW, et al. The utility of the human pa- pillomavirus DNA load for the diagnosis and prediction of persistent vaginal intraepithelial neoplasia. J Gynecol Oncol. 2009;20(4):2327. [Crossref] [PubMed] [PMC]

8. Committee on Practice Bulletins-Gynecology. Practice Bulletin No. 168: Cervical Cancer Screening and Prevention. Obstet Gynecol. 2016;128(4):e111-30. [Crossref] [PubMed]

9. Khan MJ, Massad LS, Kinney W, Gold MA, Mayeaux EJ Jr, Darragh TM, et al. A common clinical dilemma: management of abnormal vaginal cytology and human papillomavirus test results. Gynecol Oncol. 2016;141(2):364-70. [Crossref] [PubMed] [PMC] 
10. Schockaert S, Poppe W, Arbyn M, Verguts T, Verguts J. Incidence of vaginal intraepithelial neoplasia after hysterectomy for cervical intraepithelial neoplasia: a retrospective study. Am J Obstet Gynecol. 2008;199(2):113.e1-5. [Crossref] [PubMed]

11. Castle PE, Rodriguez AC, Porras $C$, Herrero R, Schiffman M, Gonzalez P, et al. A comparison of cervical and vaginal human papillomavirus. Sex Transm Dis. 2007;34(11): 849-55. [Crossref] [PubMed] [PMC]

12. Liu X, Yue Y, Zong S. Post-hysterectomy vaginal cuff cancer secondary to HPV infection and $\mathrm{CIN}$ : a case report. Pak J Med Sci. 2013;29(4):1068-70. [PubMed] [PMC]

13. Öz ZS, Demirezen Ş, Kuzey GM, Beksaç MS, Ustaçelebi Ş. Cytologic and clinical evaluation of human papillomavirus in women underwent routine gynecologic examination. Gynecology Obstetrics \& Reproductive Medicine. 2009;15(2).
14. D'Souza G, Westra WH, Wang SJ, van Zante A, Wentz A, Kluz N, et al. Differences in the prevalence of human papillomavirus (HPV) in head and neck squamous cell cancers by sex, race, anatomic tumor site, and HPV detection method. JAMA Oncol. 2017;3(2):169-77. [Crossref] [PubMed]

15. Wakeham K, Kavanagh K. The burden of HPV-associated anogenital cancers. Curr Oncol Rep. 2014;16(9):402. [Crossref] [PubMed]

16. Burd EM. Human papillomavirus and cervical cancer. Clin Microbiol Rev 2003;16(1):1-17. [Crossref] [PubMed] [PMC]

17. Castle PE, Schiffman M, Bratti MC, Hildesheim A, Herrero R, Hutchinson ML, et al. A population-based study of vaginal human papillomavirus infection in hysterectomized women. J Infect Dis. 2004;190(3):458-67. [Crossref] [PubMed]

18. Santana IU, do Nascimento Gomes A, Lyrio LDC, Grassi MFR, Santiago MB. Systemic lupus erythematosus, human papillomavirus infection, cervical pre-malignant and malignant lesions: a systematic review. Clin Rheumatol. 2011;30(5):665-72. [Crossref] [PubMed]

19. Tam LS, Chan PK, Ho SC, Yu MM, Yim SF, Cheung $\mathrm{TH}$, et al. Natural history of cervical papilloma virus infection in systemic lupus erythematosus-a prospective cohort study. J Rheumatol. 2010;37(2):330-40. [Crossref] [PubMed]

20. Rojo-Contreras W, Olivas-Flores EM, GamezNava JI, Montoya-Fuentes H, Trujillo-Hernan$\operatorname{dez} B$, Trujillo $X$, et al. Cervical human papillomavirus infection in Mexican women with systemic lupus erythematosus or rheumatoid arthritis. Lupus. 2012;21(4):365-72 [Crossref] [PubMed]

21. Raposo A, Tani C, Costa J, Mosca M. Human papillomavirus infection and cervical lesions in rheumatic diseases: a systematic review. Acta Reumatol Port. 2016;41(3):184-90. [PubMed] 